(Aus dem physiologischen Laboratorium in Bonn.)

\title{
Dr. Georg Lebbin's Entdeckeransprüche, betr. die Glykogenanalyse, werden widerlegt.
}

Von

\section{s. Pflüger.}

Die von Pflüger und Nerking veröffentlichte Methode der Glykogenanalyse ist nur eine geringfügige Abänderung des von Dr. Le b bi n (Pharm. Zeitg. Nr. 43 S. 519) ausgearbeiteten Verfahrens, so behauptet Lebbin, so wiederholen es die Berichterstatter in Maly's Jahresbericht Bd. 30 S. 446 und im Chem. Centralblatt für 1900 Bd. $2 \mathrm{~S}$. 880 . -

Die vollkommene Unrichtigkeit dieser Behauptung ergibt sich aus folgenden Thatsachen:

1. Zuerst soll, wie ja auch E. Salkow ski ${ }^{1}$ ) hervorhebt, die Fällung des Glykogenes aus alkalischer Lösung mit Alkohol schon vor mir gerade bei dieser Methode durch Le b bin ausgeführt worden sein. Dass ich einen Vorgänger bei diesem Verfahren gehabt habe, ist allerdings ein wesentlicher Punkt. Aber wie ich in der vorhergehenden Abhandlung genau bewies, ist Lebbin dieser Vorgänger nicht, weil schon der Entdecker des Glykogenes, Cl a u de Bernard, sich 1857 dieser Methode bedient hat, die seitdem sehr oft von verschiedenen Forschern in Anwendung gezogen worden ist.

2. Wenn man die bekannte Fällung des Glykogenes aus alkalischer Lösung mit Alkohol zur quantitativen Metbode erheben will, so ist natürich die erste Aufgabe, festzustellen, wie man verfahren muss, damit die Fällung eine vollständige sei. In seiner vorläufigen Mittheilung "zur quantitativen Bestimmung des Glykogenes" ist mit keiner Silbe angedeutet, dass Lebbin quantitative Versuche ausgeführt habe, um sich zu sichern, ob das Glykogen auch vollständig gefällt wurde. Nur auf diese vorläufige Mittheilung kann sich

1) Hop pe-S eyler's Zeitschr. f. physiol. Chemie Bd. 36 S. 259 , 
Lebbin uns gegenüber berufen. Denn sie ist erschienen am 20. Juli 1898. Unsere Methode ( $\mathrm{P} \mathrm{fl} \mathrm{üger} \mathrm{-N} \mathrm{erk} \mathrm{in} \mathrm{g)} \mathrm{wurde} \mathrm{veröffentlicht} \mathrm{am}$ 7. Aug. 1899. (Datum der an diesem Tage ausgegebenen Sonderabdrücke.) - Die nächste Abhandlung Lebbin's, welche nach der "vorläufigen Mittheilung" von ihm veröffentlicht ist, erschien erst am 15. September 1900 in der Zeitschrift f. öffentliche Chemie Bd. 6 S. 325-327. - Weder in der vorläufigen Mittheilung von 1898 noch in der ausführlichen befinden sich Versuche zum Beweise der vollständigen Fällbarkeit des Glykogenes durch Le b bin's Verfabren. Wir haben diesen wesentlichen Punkt durch genaue quantitative Analyse erledigt.

In einer besonderen Versuchsreihe haben wir festgestellt, dass nach der von uns ausgeführten Fällung des Glykogenes und Filtretion in dem Filtrate kein Glykogen mehr nachgewiesen werden konnte ${ }^{1}$ ).

"Es musste ferner bewiesen werden, dass bei unserer Reaction "die gefällte Substanz Glykogen ist, und dass kein Theil des Glyko"genes eine Zersetzung erfahren hat.

„Zu dem Ende wurde eine gewogene Glykogenmenge zu glykogen"freier Fleischlösung gesetzt, gefällt und mit dem angegebenen "Verfahren wieder gewonnen.

„Um unabhängig von den Verunreinigungen zu sein, wurden "solche Präparate als gleich viel Glykogen enthaltend angesehen, "welche bei der Invertirung gleich viel Zucker lieferten. Bei allen "Bestimmungen ist desshalb die Invertirung durchgeführt und das "gewonnene Kupferoxydul nach der Pflüger'schen Methode im "Asbestrohr gewogen. ${ }^{42}$ )

Es ist wahr, dass bei diesen Controlversuchen, nach B rücke$\mathrm{Külz}$ dargestelltes Glykogen verwandt worden ist. Ich glaube nicht, dass desshalb ein Vorwurf erhoben werden kann. Denn wir wissen heute, dass dieses veränderte Glykogen leichter löslich in Alkohol ist als das unveränderte. Wenn also Lebbin Glykogen mit alkoholischer Kalilauge gefällt hat, obne zu untersuchen, ob sein Verfahren quantitativ genügt, so hat er nichts Neues gebracht. Wir aber haben gezeigt, unter welehen Bedingungen die Fällung des Glykogenes aus alkalischer Lösung mit Alkohol durchgeführt werden muss, damit sie für die quantitative Analyse brauchbare Werthe

1) Dieses Archiv Bd. 76 S. 581.

2) Dieses Archiv Bd. 76 s. 532 . 
liefert. Hierin liegt eine neue Thatsache vor, und zwar ein we sent licher Unterschied gegenüber dem. Verfahren von Lebbin. Durch neuere vielfache Erfahrungen habe ich gefunden, dass eine etwas grössere Alkoholmenge; als wir sie anfangs vorschlugen, sicherer das Durchgehen von Glykogenstaub" durch : die schwedischen Filter auch ohne Jodkalium verhindert. 'Schon vor der Verbesserung: genügte die Methode in diesem Falle, wie die Controlversuche beweisen.

3. Die grosse Schwierigkeit bei der Glykogenanalyse bestand, von je her darin, das Glykogen von den grossen Eiweissmassen zu trennen, mit denen es in der nach dem Kochen erhaltenen Kalilauge gelöst ist. In Dentschland hat man viele Jahrzehnte hindurch die Methode Brücke-Külz angewandt, bei welcher das Fiweiss gefällt: wird, während das Glykogen in Lösung bleiben soll. : Tch habe die ausserordentliche Fehlerhaftigkeit dieser Methode dureh quantitative Versuche bewiesen ${ }^{1}$ ). Ebendaselbst habe ich gezeigt; wie man verfahren muss, um diese Fehler möglichst zu verkleinern. Die Brü cke Külz'sche Methode ist aber hierdurch zu einer fast unerträglich mühsamen geworden: Der Wunsch, die Trennung "des Glykogenes, vom Eiweiss umgekehrt zu versuchen, wie es schon Claude. Bernard gethan hat, nämlich das Glykogen und nicht das Eiweiss zu fällen, war also ein sehr berechtigter. Die Methode, Pflüger-Nerking leistet dies. Die Methode Lebbin's leistet. dies nicht, weil er eine zu grosse Menge von Alkohol zur Fällung. benutzt, so" dass auch Eiweissstoffe in grösserer Menge mit dem. Glykogene ausfallen. Er ist desshalb genöthigt, diese Fällung noch mit den Brücke'schen Reagentien zu reinigen, die wir vermeiden wollen.

Die Fällung 'des Glykogenes aus alkalischer Lösung mit Alkohol und gleichzeitiger, mehr oder weniger starker Verunreinigung durch mitgefälltes Eiweiss ist eine Thatsache, die seit Bernard's und Payy's Arbeiten genug gekannt ist. Lebbin's Fällungsart enthält also nichts Neues. Wir haben im Gegensatz hierzu die Bedingungen ausgemittelt, um das Glykogen möglichst frei -von Eiweiss zu fällen, und die Analysen ohne Anwendung der Brücke'schen Reagentien zu Ende geführt. Das ist ein wesentlicher Unterschied gegenüber dem Verfahren von Lebbin.

1) Dieses Archiv Bd. 75 S. 120. 
Diese allgemeine Erörterung muss ich aber sehr wesentlich durch die Bemerkung ergänzen, dass in Lebbin's "vorläufiger Mittheilung", die allein mir gegenüber in Betracht kommen kann, es sich einzig und allein handelt um die Analyse von Fleischextract. Keine Andeutung findet sich, wie man bei der Analyse glykogenhaltiger Organe verfahren soll. Also mit Organlösungen in Kalilauge, welche durch don Reichthum an Eiweiss die grossen Schwierigkeiten der Analyse bereiten, hatte Lebbin nicht gearbeitet, als er seine vorläufige Mittheilung veröffentlichte. Das haben wir aber vor ihm gethan; und das ist ein sehr wesentlich er Unterschied.

4. Nach Gewinnung des Glykogenes hat Lebbin es nach Brücke gereinigt, getrocknet, gewogen und die Asche zuweilen bestimmt. Dies Verfahren ist unglaublich langwierig und ungenau. Ich habe es ersetzt durch Bestimmung des Glykogenes als Zucker nach meiner Methode. Auch das ist ein wesentlicher Unterschied.

5. Was die neue Methode Lêb bin's werth ist, folgt aus seiner Angabe, dass das Pferdefleisch im Mittel ca. 0,7\%, Rindfleisch ca. $0,05 \%$ Glykogen enthält ${ }^{1}$ ). - - Nach zahlreichen von mir und Anderen in meinem Laboratorium ausgeführten Analysen gilt für Pferdefleisch der Werth von 1,5 bis $2,2 \%$ Glykogen, also 2 bis 3 Mal mehr; für Ochsenfleisch fand J. Nerking ${ }^{2}$ ) in drei Versuchsreihen $0,83 \%, 0,91 \%, 1,4 \%$ Glykogen, also 16 bis 28 Mal mehr. Bei Pferden und Ochsen kommen natürlich zuweilen auch sebr niedrige Werthe vor. -

Lebbin's Behauptung, dass die Methode Pflüger-Nerking nur eine "geringfügige" Abänderung seines Verfahrens sei, ist eine so grosse Entstellung des wirklichen Sachverhaltes, dass ich darauf zu antworten verzichtete. Erst Salkowski's Beistimmung, sowie die Haltung der Berichterstatter in den Jahresberichten zwangen mich zur Vertheidigung.

1) Zeitschr. f. öffentl. Chemie Bd. 6 S. 327.

2) Dieses Archiv Bd. 81 S. 12, 15, 17. 